Oxford handbook of tropical medicine

by Michael Eddleston and Stephen Pierini. Oxford University Press, 1999. 666pp. £19.99.

The Oxford handbook of tropical medicine is intended to be a practical guide, as well as a reference text for junior doctors working in tropical countries, particularly where more senior support is unavailable. For quick access, emergencies are clearly indexed on the first page. The introductory chapter emphasises the importance of local traditional health care systems, because they are the main source of everyday health care for most of the population in developing countries. Collaboration with and cross-referral to local traditional practitioners are valuable ways to integrate traditional practices and modern medicine. With on-line databases becoming more readily accessible in developing countries the authors include useful suggestions for isolated doctors to find evidence-based backup for their actions. Guidelines and algorithms, often drawn from the WHO, are also supplied. Key information on specific treatment regimen is highlighted in separate boxes. Descriptions of practical procedures are also included.

Tropical infectious diseases justifiably occupy the first half of this book. But systemic diseases that are common in other parts of the world are also common in tropical countries. Since the authors' aim is to provide information and guidance on medical problems likely to be encountered by doctors working in isolation, the second half includes descriptions of the diagnosis and management of systemic diseases, preceded by a short review of basic knowledge. I found these chapters a helpful and readable synopsis of medicine in the tropics, and would recommend it to any junior doctor planning to work in areas where experienced back-up may be thin on the ground.

YUPIN SUPUTTAMONGKOL Department of Medicine, Siriraj Hospital, Bangkok

\section{Caring for Muslim patients}

Edited by Aziz Sheikh and Abdul Rashid Gatrad. Oxford: Radcliffe Medical Press, 2000. 160pp. £17.95.

How would you handle a diabetic Muslim patient who wants to fast for Ramadan? Did you know that performing the pilgrimage to Mecca requires meningitis $\mathrm{A} \& \mathrm{C}$ vaccination, and that women would wish to avoid menstruation during the Hajj? Do the relatives of your patient know that a recent Fatwa condones Muslims donating organs in the UK? Knowing the answers to such questions will help your Muslim patients to realise the words of Sa'di (one of the greatest figures in classical Persian literature), which begin this book: 'When you were born, everyone was smiling but you were crying. Live such a life that, when you depart, everyone is weeping but you are smiling. Empowered by knowledge, healthcare professionals can make a huge difference to, amongst many things, the birth and death of Muslims, illustrated by the other poignant quote of the book from an intensive care nurse: 'We asked the family if they wanted their son's bed facing towards Mecca - they were really taken aback, and so appreciative of such a small gesture'.

You can read this concise multi-authored work in an evening, learning about Islam in the first section and particular patient scenarios in the second, keeping the book to hand thereafter for quick reference to its well-researched appendices in the third section. To the editors' credit their subtext seeks to encourage our enlightenment, rather than to combat the cultural stereotypes that have helped ignorance breed 'Islamophobia'. The content is well structured, and balances explanatory background details with practical advice, although one is sometimes left asking yet more questions. The answers can be found using their appendix of useful websites, although it has inevitably become out of date (at least three of their thirty-four website addresses no longer exist).

This book's readership should encompass not only the whole multidisciplinary healthcare team, but also hospital managers (does your appointment booking service have a multicultural calendar, do your medical records staff know the few simple rules about Islamic names, and is there a copy of the Qur'an on each ward?), coroners (would you insist on a post mortem for a Muslim patient only if required for medico-legal purposes?), researchers and medical anthropologists. If you do not buy a copy, your hospital or medical practice library should have one for reference, especially if you work in one of the areas where the Muslim population of the UK (currently $2 \%$ ) is expanding.

After reading this book you might well join us by saying, in praise of it, al-hamdu-lillah!

RUSTAM AL-SHAHI MRC Clinical Training Fellow, Department of Clinical Neurosciences, University of Edinburgh

AHMED AL-SHAHI Social Anthropologist and Senior Associate Member, St Antony's College, University of Oxford 